\title{
Validation of tropical artificial soil by chronic toxicity studies on Eisenia fetida against superphosphate
}

\author{
K. S. Abbiramy ${ }^{1, a}$, P. Ronald Ross ${ }^{2, b}$, J. Paramanandham ${ }^{3, c}$ \\ ${ }^{1}$ Research Scholar, Department of Zoology, Annamalai University, \\ Annamalainagar - 608 002, Tamilnadu, India \\ Phone: +91-4364-273699, Mobile: +919884720208 \\ ${ }^{2}$ Zoology Wing, Annamalai University, Annamalainagar - 608 002, Tamilnadu, India \\ ${ }^{3}$ Research Scholar, Department of Zoology, Annamalai University, \\ Annamalainagar - 608 002, Tamilnadu, India \\ a,b,cE-mail address: umak.senthil@gmail.com ,r_ross1971@yahoo.co.in , \\ paramusacon2010@gmail.com
}

\begin{abstract}
The research methodology recommended by the OECD (Organization of Economic Cooperation and Development) and ISO (International Organization for Standardization) guidelines for testing of chemicals meets the most criteria expected for ecotoxicological testing except the testing condition and the organic matter. The guidelines were initially developed by temperate countries, with testing conditions as $20^{\circ} \mathrm{C}$ and the organic matter as sphagnum peat which is commonly available in those countries. But these two criterions are difficult to be followed in tropical countries. Thus there arises a need of modifying these criterions for toxicity studied in tropical regions. In this study a trial was made for substituting the fermented coir pith for sphagnum peat and the validation of the modified tropical artificial soil (TAS) was done by conducting chronic toxicity studies on Eisenia fetida against an inorganic fertilizer, superphosphate (SP) under tropical condition, i.e., $28 \pm 2{ }^{\circ} \mathrm{C}$. The performed study showed that the SP determined lower earthworm mortality in TAS comparing to OECD soil for all tested concentration levels. The number of juveniles produced in OECD soil was also significantly reduced $(\mathrm{p}<0.05)$ than in TAS. This may be due to the production of large amount of hydrogen ions when the temperature increases and making the medium acidic. The fermented coir pith was more suitable for ecotoxicity studies under tropical condition than sphagnum peat.
\end{abstract}

Keywords: OECD soil; Tropical Artificial Soil; Superphosphate; Chronic toxicity tests; Eisenia fetida

\section{INTRODUCTION}

The concern regarding the effect of the toxic substances on the environment is growing rapidly in whole world and the efforts to develop more reliable methods for evaluating the side-effects on non-target organisms are being increased. Toxicity tests provide a direct measure of the effects of toxicants and can help establish linkages between site contamination and adverse ecological effects. Toxicity tests evaluate acute and chronic exposures and measure biological endpoints such as mortality, reproductive performance, growth and 
behavioural changes (Lee et al, 2007). In order to test the ecotoxicity of some substances on earthworms, an essential importance is attributed to the test soil, because earthworms are organisms whose life environment is represented by soil.

Ecotoxicological studies are normally carried out in artificial soil proposed by OECD (Organization of Economic Co-operation and Development) and ISO (International Organization for Standardization) guidelines. These guidelines were written focusing on the situation in countries of temperate regions. In these countries, the components of artificial soil particularly, the sphagnum peat moss is easily obtained. However, in order to allow its use in other regions of the world where the sphagnum peat moss is not readily available, some modifications are necessary.

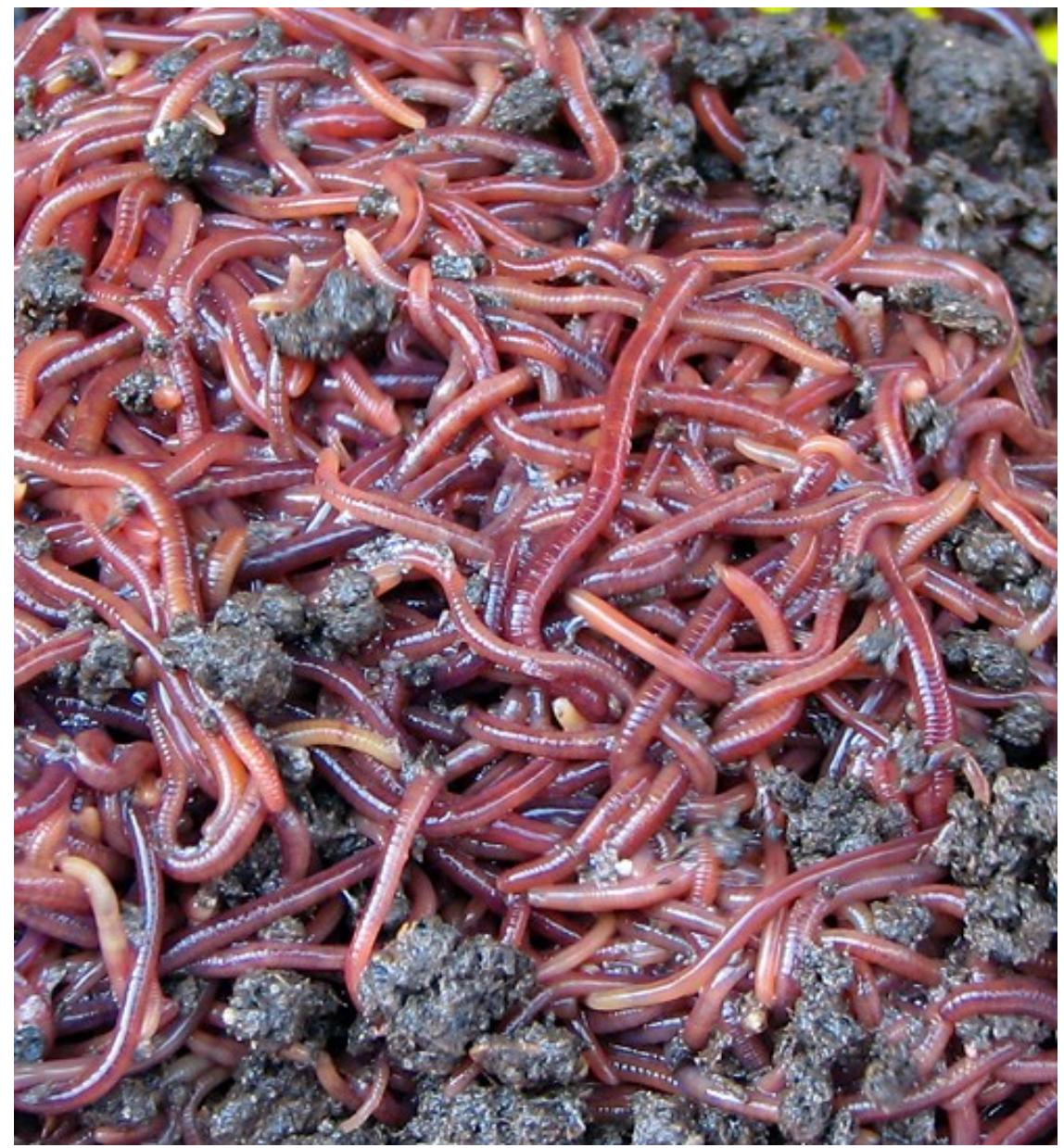

Photo 1. Eisenia fetida.

Thus, this study aimed to determine the suitability of fermented coir pith as an alternative organic matter $(\mathrm{OM})$ in the artificial soil, planning to contribute to the construction of such a scientific basis for tropical soil ecotoxicology. Though the OECD artificial soil test for earthworms is well established and has been in place for decades, the reproducibility as substrate sustaining growth and reproduction of earthworms for sub-lethal laboratory tests, has been an issue addressed in one way or another, by various authors (OECD, 1984a; Arnaud et al, 2000; Spurgeon et al, 2003; Kuperman et al, 2004; Van Gestel and Weeks, 2004 and Spurgeon et al, 2004). Ideally, a modified tropical artificial soil (TAS) 
that allowed the study of growth and reproduction of E. fetida over 56 days has been developed incorporating fermented coir pith as OM and tested using SP at sub-lethal levels.

The only difference in both the soils (OECD soil and TAS) is the organic matter. Sphagnum peat is obtained commercially from nurseries or stores which often contains the dry, nutrient-poor and decomposed sphagnum moss. The fresh sphagnum peat moss has a $\mathrm{pH}$ of approximately 4.0, according to the Iowa State University Extension. Sphagnum moss thrives in acidic conditions and will actually add acidity to the soil and water when the temperature rises.

Thus ecotoxicological studies with sphagnum peat as organic component in tropical regions is not feasible. Hence an alternate organic component for artificial soil was a need and fermented coir pith from coconut peel (Cocos nucifera L.) was tested for validity. In order to determine the influence of the two different soils on the earthworms, superphosphate was selected as model compound.

SP is a worldwide used chemical fertilizer that is applied to crops for supplying phosphorus. Thus in this investigation, validation of artificial soil with fermented coir pith as OM was done by conducting the chronic toxicity tests with SP on Eisenia fetida under tropical condition (i.e. at $28 \pm 2{ }^{\circ} \mathrm{C}$ ).

\section{MATERIALS AND METHODS}

\section{1. Preparation of test substrates}

In this study two different artificial soils had been identified for laboratory tests, the OECD soil and tropical artificial soil (TAS). The preparation of both the test substrates was based on an international guideline published by OECD but replacing fermented coir pith instead of sphagnum peat in TAS (OECD, 1984a). The standard temperature was also modified as $28 \pm 2{ }^{\circ} \mathrm{C}$ instead of $20^{\circ} \mathrm{C}$.

The quartz sand and kaolinite clay (air dried) were purchased from Himedia Chemical Laboratories, Bengalure, India. Sphagnum peat moss was bought from a nursery situated in Ottathycal, Coimbatore, India. The material was ground after drying it at room temperature and used as a part of the substrate. The other organic matter, coir pith was procured from the coir mounts closer to the coir industry located in Kullanchavadi village, Cuddalore, India. Coir pith was initially sieved and then fermented in plastic round tubs for 30days, air dried and then used as component.

All dry constituents (70\% sand, $20 \%$ kaolinite clay and $10 \% \mathrm{OM}$ ) were thoroughly mixed and $\mathrm{pH}$ was adjusted to $6.0 \pm 0.5$ with calcium carbonate. The $\mathrm{pH}$, moisture content and water holding capacity were measured according to the ISO guidelines (ISO, 1993b and ISO, 1994). The organic components of the artificial soils and the artificial soils prepared were physico-chemically analyzed (Table 1) before implementation.

\section{2. Test organism and its mass culture}

Mass culture of E. fetida was established in laboratory from samples provided from the vermicomposting unit of Annamalai University for both artificial soils in cement tanks $(40 \mathrm{x}$ $35 \mathrm{~cm}$ area, $30 \mathrm{~cm}$ height). The temperature of both the cultures was maintained at room temperature $22-30{ }^{\circ} \mathrm{C}$ (mean $=26^{\circ} \mathrm{C}$ ) with relative air humidity near $90 \%$. The animals were maintained in a shaded place with a natural light cycle (12h light/12h dark). The breeding substrate (cow dung devoid of contamination) was maintained with a $\mathrm{pH}$-value set to $6 \pm 0.5$. The moisture was adjusted to $50 \pm 10 \%$ dry weight using deionized water. 


\section{3. Test chemical and solution preparation}

The test chemical, SP was obtained from the Preliminary Agricultural Co-operative Bank, Annamalai Nagar, India. Normal SP refers to fertilizer material containing 15 to 21 percent phosphorus as phosphorus pentoxide $\left(\mathrm{P}_{2} \mathrm{O}_{5}\right)$. SP were prepared by reacting ground phosphate rock with 65 to 75 percent sulfuric acid.

An important factor in the production of normal superphosphates is the amount of iron and aluminum in the phosphate rock. Aluminum $\left(\right.$ as $\left.\mathrm{Al}_{2} \mathrm{O}_{3}\right)$ and iron $\left(\right.$ as $\left.\mathrm{Fe}_{2} \mathrm{O}_{3}\right)$ above 5 percent imparts an extreme stickiness to the SP and makes it difficult to handle. The preparation of the test solutions was done for each concentration by weighing and dissolving an amount of SP in one litre of deionized water. Deionized water was obtained using reverse osmosis water purifier and was used throughout this study. All glass wares were washed with phosphate-free detergent, rinsed with acetone, and acid-washed before a final and thorough rinse with deionized water.

\section{4. Experimental design}

As the range-finding test (RF test) and the acute test were already performed for superphosphate with earthworms, (Abbiramy et al, 2014) using the same test substrates and the $\mathrm{LC}_{50}$ values were calculated, the concentrations to be used in the chronic tests were chosen as sublethal i.e. $1 / 32,1 / 16,1 / 8,1 / 4$ and $1 / 2$ of SP's $\operatorname{LC}_{50}$ values (i.e. 184.37, 368.75, $737.5,1475$ and $2950 \mathrm{mg} / \mathrm{kg}$ for OECD soil and 375, 750, 1500, 3000 and $6000 \mathrm{mg} / \mathrm{kg}$ for TAS).

\section{4. Chronic toxicity tests}

The test system for the determination of the chronic toxicity of SP to earthworms was based on the guidelines OECD no. 222 and ISO-11268-2 (OECD, 2003 and ISO, 1993a). Tests with E. fetida were done according to the guidelines but at tropical conditions (i.e. 28 ${ }^{\circ} \mathrm{C}$ ) by using the two test substrates.

Only adult earthworms (with clitellum) with a fresh weight between 250 and $400 \mathrm{mg}$ were used for reproduction tests. The selected test animals were acclimatized in an untreated test substrates atleast 24 hours prior to the start of the test. SP was mixed in different concentrations in the test substrates and was applied only once at the beginning of the test.

The test period was 56 days. Pure cow dung was provided as food placed on top, in holes once in a week (Van Gestel et al, 1991; Gibbs et al, 1996 and OECD, 2004). After 28 days, the adult worms which were removed from the test vessels and tested for mortality and biomass. During the following 28 days, juveniles were hatched from cocoons laid by the adults. Test parameters were mortality and biomass development of the adults 28 days after application and the number of juveniles 56 days after application.

During the 56 days of test, the moisture was kept near the initial value and the $\mathrm{pH}$ varied from 0.3 to 0.5 units up or down. The reproductive output of the worms exposed to the test substance was compared to that of the control in order to determine the (i) no observed effect concentration (NOEC) and (ii) $\mathrm{EC}_{50}$ by using a regression model to estimate the concentration that would cause a $50 \%$ reduction in reproductive output.

\section{RESULTS}

Selected physico-chemical properties of the standard OECD soil and the modified tropical artificial soils are given in Table 1. The organic matter and the soils differed 
markedly in certain properties, especially in $\mathrm{pH}$. The raw sphagnum peat was acidic followed by the slightly acidic OECD soil prepared initially which was then neutralized by the addition of $\mathrm{CaCO}_{3}$. The $\mathrm{pH}$ of fermented coir pith and the TAS was closer to neutral. Higher $\mathrm{Ca}, \mathrm{Mg}$, $\mathrm{K}, \mathrm{S}, \mathrm{Mn}$ and $\mathrm{Z}$ contents were found in fermented coir pith than the sphagnum peat.

Table 1. Physico-Chemical characteristics of organic matters and the artificial soils.

\begin{tabular}{|c|c|c|c|c|}
\hline Characteristics & $\begin{array}{c}\text { Sphagnum } \\
\text { Peat Moss }\end{array}$ & $\begin{array}{c}\text { Fermented } \\
\text { Coir pith }\end{array}$ & $\begin{array}{c}\text { OECD } \\
\text { soil }\end{array}$ & TAS \\
\hline $\mathrm{pH}\left(\mathrm{CaCl}_{2}\right)$ & 4.77 & 6.9 & 6.1 & 6.8 \\
\hline $\mathrm{P}(\mathrm{mg} / \mathrm{kg})$ & 0.19 & 30 & 11 & 27 \\
\hline $\mathrm{K}(\mathrm{mg} / \mathrm{kg})$ & 91 & 480 & 104 & 324 \\
\hline $\mathrm{Ca}(\mathrm{mg} / \mathrm{kg})$ & 2.13 & 9.08 & 1.29 & 2.46 \\
\hline $\mathrm{Mg}(\mathrm{mg} / \mathrm{kg})$ & 0.94 & 0.9 & 0.55 & 0.56 \\
\hline $\mathrm{S}(\mathrm{mg} / \mathrm{kg})$ & 1.97 & 0.47 & 0.9 & 0.8 \\
\hline $\mathrm{B}(\mathrm{mg} / \mathrm{kg})$ & 6.6 & 7.1 & 1.3 & 1.7 \\
\hline $\mathrm{Cu}(\mathrm{mg} / \mathrm{kg})$ & 2.5 & 3.9 & 0.02 & 0.74 \\
\hline $\mathrm{Fe}(\mathrm{mg} / \mathrm{kg})$ & 514 & 165 & 9.0 & 8.0 \\
\hline $\mathrm{Mn}(\mathrm{mg} / \mathrm{kg})$ & 9.0 & 7.4 & 0.41 & 0.58 \\
\hline $\mathrm{Zn}(\mathrm{mg} / \mathrm{kg})$ & 34.0 & 11.2 & 1.30 & 2.54 \\
\hline Organic Carbon $(\%)$ & 4.2 & 6.5 & 2.11 & 3.926 \\
\hline Organic Matter $(\%)$ & 7.24 & 11.20 & 3.637 & 6.768 \\
\hline Total N (\%) & 0.72 & 0.5 & 0.1 & 0.19 \\
\hline $\mathrm{WHC}(\%)$ & 59.1 & 45.71 & 46.1 & 48.5 \\
\hline $\mathrm{CN} \mathrm{Ratio}$ & 5.83 & 22.41 & 17.23 & 20.66 \\
\hline
\end{tabular}

When the soils were compared the ion content was higher in TAS than the OECD soil. The concentration of essential elements such as NPK was higher in tropical soil than in OECD soil. The same was inferred for water holding capacity, organic carbon content, organic matter content and $\mathrm{C} / \mathrm{N}$ ratio. The highest water holding capacity was recorded in sphagnum peat.

\section{1. Chronic toxicity tests}

In the present study, the chronic toxic effects of fertilizer, SP spiked in two different artificial soils were examined on E. fetida using the 56 days reproduction test. Mortality and biomass development of the adults after 28 days exposure and the number of juveniles after 
56 days exposure were compared with nominal as well as the test concentrations in the two soils.

Covering the concentration range between 184.37 and $6000 \mathrm{mg} / \mathrm{kg}$, the effect of SP on the number of juveniles differed in its figure under tropical condition. The test in OECD soil was considered as not valid because the number of juveniles in the control was less than 30 (Table 2). Thus no data could be calculated from the tests with OECD soil. The juvenile number decreased gradually in TAS as the concentration increased (Table 3). The estimated $\mathrm{EC}_{50}$ value of TAS was $3117.2 \mathrm{mg} / \mathrm{kg}$ (Table 4) but the confidence limits were not estimated. The dose response curve showed a shallow decrease of juvenile numbers for the tropical soil (Fig. 1). Less than $10 \%$ mortality of adults after 28 days occurred in TAS. But the mortality in OECD soil was significantly higher, reaching $25 \%$ at the highest concentration of SP.

Table 2. Chronic toxicity of Eisenia fetida in superphosphate-dosed OECD soil under tropical condition.

\begin{tabular}{|c|c|c|c|c|c|}
\hline $\begin{array}{c}\text { Concentrations } \\
\text { in mg/kg }\end{array}$ & $\begin{array}{c}\text { Adult } \\
\text { Mortality }\end{array}$ & $\begin{array}{c}\text { Biomass on } \\
\text { initial day }\end{array}$ & $\begin{array}{c}\text { Biomass on } \\
\mathbf{2 8}^{\text {th }} \text { day }\end{array}$ & $\begin{array}{c}\text { Number of } \\
\text { Juveniles }\end{array}$ & $\begin{array}{c}\text { Juveniles \% } \\
\text { of the } \\
\text { control }\end{array}$ \\
\hline Control & 2.5 & $320.0 \pm 20.1$ & $291.4 \pm 10.8$ & $15.3 \pm 6.8$ & 100.0 \\
\hline $\mathbf{1 8 4 . 3 7}$ & 12.5 & $319.0 \pm 17.5$ & $317.3 \pm 47.9$ & $12.0 \pm 10.8$ & 78.4 \\
\hline $\mathbf{3 6 8 . 7 5}$ & 5.0 & $319.2 \pm 15.4$ & $278.2 \pm 28.7$ & $7.3 \pm 5.3$ & 47.7 \\
\hline $\mathbf{7 3 7 . 5}$ & 5.0 & $318.4 \pm 14.1$ & $265.1 \pm 30.1$ & $4.3 \pm 4.0$ & 28.1 \\
\hline $\mathbf{1 4 7 5}$ & 2.5 & $318.9 \pm 13.7$ & $289.5 \pm 42.1$ & $1.3 \pm 1.9$ & 8.4 \\
\hline $\mathbf{2 9 5 0}$ & 25.0 & $320.4 \pm 14.3$ & $189.6 \pm 9.8$ & 0.0 & 0.0 \\
\hline
\end{tabular}

Table 3. Chronic toxicity of Eisenia fetida in superphosphate-dosed TAS under tropical condition.

\begin{tabular}{|c|c|c|c|c|c|}
\hline $\begin{array}{c}\text { Concentrations } \\
\text { in mg/kg }\end{array}$ & $\begin{array}{c}\text { Adult } \\
\text { Mortality }\end{array}$ & $\begin{array}{c}\text { Biomass on } \\
\text { initial day }\end{array}$ & $\begin{array}{c}\text { Biomass on } \\
\mathbf{2 8}^{\text {th }} \text { day }\end{array}$ & $\begin{array}{c}\text { Number of } \\
\text { Juveniles }\end{array}$ & $\begin{array}{c}\text { Juveniles \% } \\
\text { of the } \\
\text { control }\end{array}$ \\
\hline Control & 0.0 & $390.5 \pm 17.8$ & $544.8 \pm 36.6$ & $205.8 \pm 30.5$ & 100.0 \\
\hline $\mathbf{3 7 5}$ & 0.0 & $394.4 \pm 47.9$ & $535.6 \pm 18.9$ & $186.5 \pm 29.7$ & 90.6 \\
\hline $\mathbf{7 5 0}$ & 0.0 & $384.4 \pm 28.9$ & $563.2 \pm 41.5$ & $195.3 \pm 13.2$ & 94.9 \\
\hline $\mathbf{1 5 0 0}$ & 0.0 & $381.7 \pm 31.8$ & $527.2 \pm 21.5$ & $127.8 \pm 35.1$ & 62.1 \\
\hline $\mathbf{3 0 0 0}$ & 0.0 & $390.8 \pm 23.6$ & $567.6 \pm 48.9$ & $156.1 \pm 23.3$ & 65.2 \\
\hline $\mathbf{6 0 0 0}$ & 5.0 & $394.2 \pm 25.5$ & $329.6 \pm 33.1$ & $0.8 \pm 0.5$ & 0.4 \\
\hline
\end{tabular}


Table 4. Chronic toxicity of Eisenia fetida in superphosphate-dosed substrate under tropical condition: $\mathrm{EC}_{50}$ and its $95 \%$ - confidence limits and NOEC (values in $\mathrm{mg} / \mathrm{kg}$ ).

\begin{tabular}{|c|c|c|}
\hline & OECD soil & TAS \\
\hline EC $_{50}$ & n.d. & $3117.2[95 \% \mathrm{CL}-$ n.d. $]$ \\
\hline NOEC & n.d. & 43.7 \\
\hline
\end{tabular}

n.d. - not determined

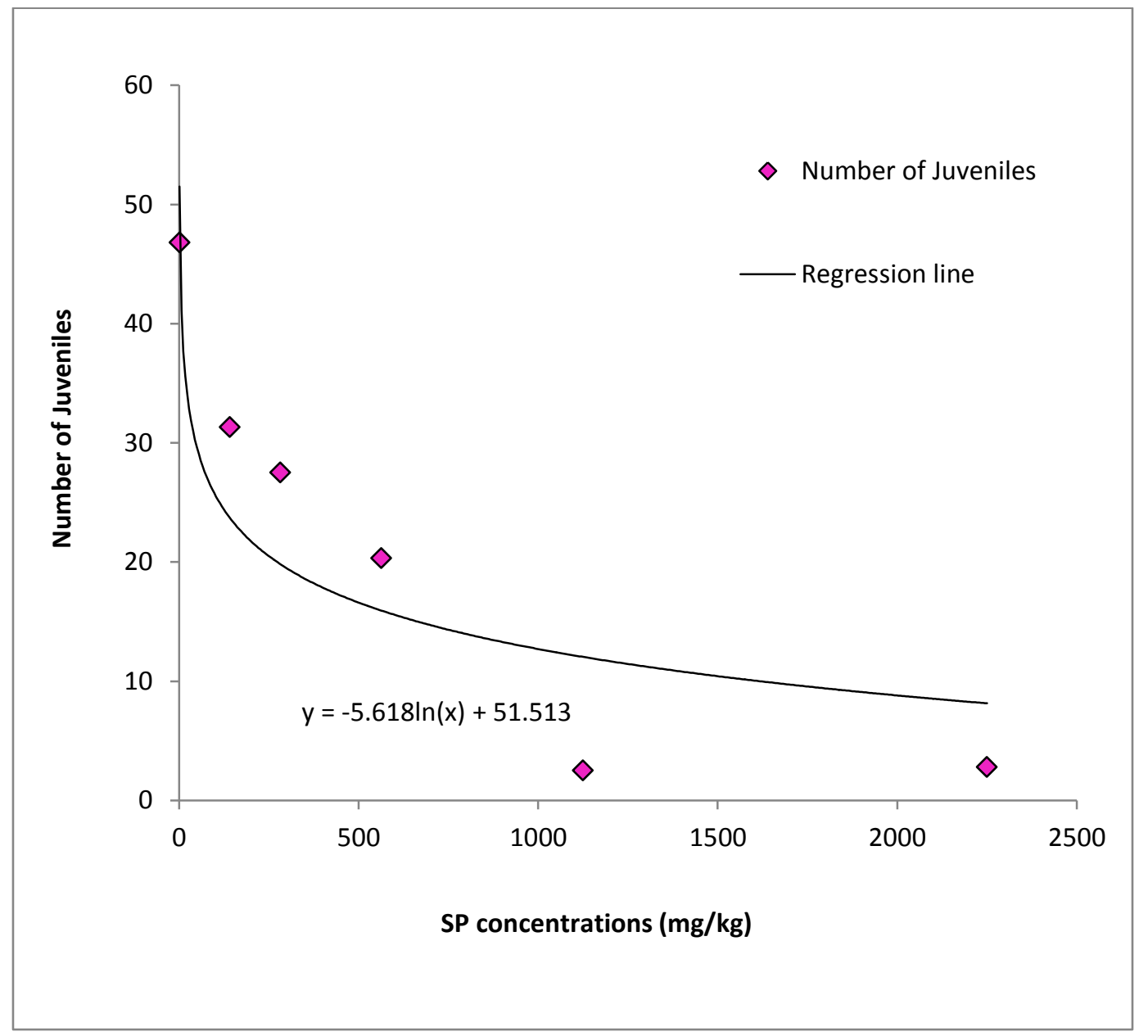

Figure 1. Dose response curve in the chronic toxicity test with Eisenia fetida in SP-dosed TAS under tropical condition.

\section{DISCUSSION}

Despite the fact that earthworms are widely used in ecotoxicological research, no official guideline is so far available for the tropical countries. Protocols for temperate regions have been proposed by OECD and ISO to evaluate the effects on growth and reproduction (OECD, 2003 and ISO, 1998a). But there are no separate protocols or standardization 
proposed for tropical regions and more data (especially with agrochemicals) is being required. Further progress has been made for developing and improving the substrate and conditions (temperature) considering the tropical condition and the availability of the organic matter.

Toxicity studies were also made with pesticides and herbicides on earthworms (De Silva, 2009; Eijsackers, 1978; Subagja and Snider, 1981; Eijsackers, 1991; Van Gestal et al, 1992 and Xiao, 2004). But studies on toxic effect of fertilization of soil on earthworms were very rare. Thus this study was aimed at studying the chronic toxicity of fertilizer, SP on earthworm Eisenia fetida using the method proposed by OECD (2003). It is well accepted that there is a fundamental shortage of data regarding the possible adverse effects of environmental contaminants on biological life in soil (Eijsackers, 1997). There are more current laboratory test methods outlined, but it is very important the major advantages/disadvantages of each of them.

Nearly no data on the toxicity of fertilizers to earthworms exist. The only literature available was the work of Xiao et al. (2004) on the acute toxicity of urea (fertilizer) and the combined effect of urea and acetochlor (herbicide). The 14 days $\mathrm{LC}_{50}$ of urea to earthworms was determined as $1065.9 \mathrm{mg} / \mathrm{kg}$ using the natural soil of Phaiozem, China as substrate and not on standardized soil. Only the acute effect of urea on earthworm was studied and not the chronic effects. This was the maiden attempt to study the chronic toxic effect of fertilizer, SP on earthworms.

The organic matter and the soils differed markedly in certain properties, especially in $\mathrm{pH}$ and higher $\mathrm{Ca}, \mathrm{Mg}, \mathrm{K}, \mathrm{S}, \mathrm{Mn}$ and $\mathrm{Z}$ contents were found in fermented coir pith than the sphagnum peat. Noguera et al. (2000) have earlier reported similar physico-chemical parameters of peat and coir pith but no comparative studies with fermented coir pith and sphagnum peat as an OM of artificial soil could be found in the literature.

The mortality in OECD soil was significantly higher $(25 \%)$ at the highest concentration of SP. Thus this soil when used for ecotoxicological studies to observe the effect of chemicals will not give promising results under tropical condition. Also the biomass of the adult earthworms was affected significantly (Table 2). No such effect on adult worms was observed in TAS. In fact, an increase was observed in lower concentrations of SP (Table 3 ). A sequential decrease in the mean number of juveniles was observed as the concentration of SP increased but the tests were not valid in OECD soil as the number of juveniles was less than 30 .

\section{CONCLUSIONS}

OECD founded in 1961 in Paris, France, provided the method of artificial soil test which meets the most criteria expected for ecotoxicological testing known as OECD Guideline for testing of chemicals 207 adopted in April 1984. Though the OECD artificial soil test for earthworms is well established and has been in place for decades, the reproducibility as substrate sustaining growth and reproduction of earthworms for lethal and sub-lethal laboratory tests under tropical condition, has been an issue addressed by various authors. Thus this work has been done to develop a modified tropical artificial soil (TAS) and to validate its eligibility by assessing the effects of lethal and sub-lethal levels of SP.

The performed study showed the following conclusions:

The fertilizer SP determined lower earthworm mortality in TAS comparing to OECD soil for all tested concentration levels. The fertilizer SP positively influenced the earthworm 
rate of biomass accumulation in lower SP concentrations in TAS but the lower concentrations itself was toxic to earthworms in OECD soil. The fertilizer SP determined a $2.5 \%$ mortality of earthworms in control OECD soil which requires a precaution attitude regarding its use in ecotoxicological studies under tropical condition, while the attentive establishment of the TAS can be recommended.

\section{References}

[1] Lee B. T., Shin K. H., Kim J. Y., Ki K. W., Progress in earthworm ecotoxicology, in Advanced Environmental Monitoring, (2007) Springer Netherlands..

[2] Arnaud C., Saint-Denis M., Narbonne J. F., Soler P., Ribera D., Soil Biol Biochem 32 (2000) 67-73.

[3] Spurgeon D. J., Weeks J. M., Van Gestel C. A. M., Pedobiologia 47 (2003) 588-606.

[4] Kuperman R. G., Checkai R. T., Simini M., Phillips C. T., Ecotox Environ Safety 57 (2004) 48-53.

[5] Van Gestel C. A. M., Weeks J. M., Ecotox Environ Safety 57 (2004) 100-105.

[6] Spurgeon D. J., Svendsen C., Kille P., Morgan A.J., Weeks J.M., Ecotox Environ Safety 57 (2004) 54-64.

[7] ISO. International Organization for Standardization. ISO-11465: Geneve, Switzerland $1993 b$.

[8] ISO. International Organization for Standardization. ISO-10390: Geneve, Switzerland 1994.

[9] Abbiramy K. S., P. Ronald Ross, J. Paramanandham, Res J Chem Env Sci 2 (2014) 29-35.

[10] OECD. Organization of Economic Cooperation and Development. Guideline for Testing of Chemicals No. 222, Paris 2003.

[11] ISO. ISO-11268-2: International Organization for Standardization, Geneva, Switzerland $1998 \mathrm{a}$.

[12] Van Gestel C. A. M., Van Dis W. A., Dirven-van Breemen E. M., Sparenburg P. M., Baerselman R., Biol Fert Soils 12 (1991) 117-121.

[13] Gibbs M. H., Wicker L. F., Stewart A., J. Environ Toxicol Chem 15 (1996) 360-368.

[14] OECD. Adopted April 132004.

[15] De Silva, PMCS. Ph.D. Thesis, VU Amsterdam, The Netherlands. (2009) 117.

[16] Eijsackers H., Z Ang Ent 86 (1978) 349-372.

[17] Eijsackers H., Neth J Zool 41 (1991) 277-303.

[18] Subagja J., Snider R. J., Pedobiologia 22 (1981) 141-152.

[19] Van Gestel C. A. M., Dirven-Van Breemen E. M., Baerselman R., Emans H. J. B., Janssen J. A. M., Postuma R., Van Vliet P. J. M., Ecotox Environ Safety 23 (1992) 206-220. 
[20] Xiao H., Zhou Q. X., Liang J. D., Environ Geo chem Health 26 (2004) 277-283.

[21] Eijsackers H., Soil ecotoxicology: Chapman \& Hall, London, UK, (1997) 323-330.

[22] Noguera P., Abad M., Noguera V., Puchades R., Maquieira A., Acta Hortic 517 (2000) 279-286. 